\title{
BMJ Open Attitudes of medical professionals towards patient-centredness: a cross- sectional study in H City, China
}

\author{
Weijian Song (10 , ${ }^{1,2}$ Yanhua Hao, ${ }^{1}$ Yu Cui, ${ }^{1}$ Xiaowen Zhao, ${ }^{1}$ Wei Liu, ${ }^{1}$ Siyi Tao, ${ }^{1,3}$ \\ Yuxin Xue, ${ }^{4}$ Chaojie Liu (1) , ${ }^{5}$ Qiao Zhang, ${ }^{1}$ Mingli Jiao (D) ,, Weilan Xu, ${ }^{6}$ Hong Sun, ${ }^{1}$ \\ Ye Li, ${ }^{1}$ Linghan Shan, ${ }^{1}$ Juan Zhao, ${ }^{1}$ Libo Liang (D) , ${ }^{1}$ Qunhong Wu (D) ${ }^{1}$
}

To cite: Song W, Hao Y, Cui Y, et al. Attitudes of medical professionals towards patientcentredness: a cross-sectional study in $\mathrm{H}$ City, China. BMJ Open 2022;12:e045542. doi:10.1136/ bmjopen-2020-045542

- Prepublication history for this paper is available online. To view these files, please visit the journal online (http://dx.doi org/10.1136/bmjopen-2020045542).

WS and MJ contributed equally.

Received 09 0ctober 2020 Accepted 07 January 2022

Check for updates

(C) Author(s) (or their employer(s)) 2022. Re-use permitted under CC BY-NC. No commercial re-use. See rights and permissions. Published by BMJ.

For numbered affiliations see end of article.

Correspondence to Professor Libo Liang; llbhit@163.com and Professor Qunhong Wu; wuqunhong@163.com

\section{ABSTRACT}

Objectives Patient-centred communication improves patient experiences and patient care outcomes. This study aimed to assess the preference of medical professionals in China towards patient-centred communication under the context of the deteriorating doctor-patient relationship. Methods A cross-sectional survey of medical professionals was conducted in January and February 2018 in H City of Heilongjiang province, the northeast of China. The Chinese-Revised Patient-Practitioner Orientation Scale (CR-PPOS) was adopted to measure the individual preference of respondents towards patientcentredness in clinical communication. Multivariate logistic regression models were established to identify the sociodemographic (gender, age, marital status and educational attainment) and work experience (years of working, seniority, satisfaction with income, daily workload and perceived doctor-patient relationship) predictors of the preference towards patient-centredness.

Patient and public involvement Not applicable.

Results A total of 618 valid questionnaires were returned. The CR-PPOS demonstrated acceptable reliability and validity. Overall, a low level of preference towards patient-centredness in clinical communication was found. Relatively higher scores on 'caring for patients' $(20.42 \pm 4.42)$ was found compared with those on 'information/responsibility sharing' $(15.26 \pm 4.21)$. Younger age, higher educational attainment, lower daily workload and a perception of harmonious doctor-patient relationship were associated with a higher preference towards patient-centredness in clinical communication. Conclusions A low level of preference towards patientcentredness in clinical communication was found in medical professionals in the northeast of China, which may further jeopardise the efforts to improve doctor-patient relationship.

\section{INTRODUCTION}

With the shift to the biopsychosocial paradigm, people have become increasingly concerned about the orientation of medical professionals towards clinical communication with their patients. Studies have distinguished between the patient-oriented style versus a doctor-oriented style of interaction. $^{1-3}$ The origin of the concept of

\section{Strengths and limitations of this study}

- This study is the first of its kind in the northeast of China using the Chinese-Revised PatientPractitioner Orientation Scale.

- The study adopted a cross-sectional design with a large sample size, which can help improve our understanding on the attitudes of medical professionals towards patient-centredness in clinical communication.

- The findings have significant implications on the management of medical practice under the specific context of China.

- The study identified sociodemographic and work experience predictors of the preference of medical professionals towards patient-centredness in clinical communications, but no causal relationships can be assumed due to the cross-sectional design.

patient-centred care can be traced back to the ancient time of Hippocrates when each patient was considered as a relatively independent individual. ${ }^{4}$ The fundamental principles of patient-centredness, however, have not been consistently defined until recently. It generally refers to the establishment of a partnership between providers and patients for the purpose of care tailored to the individual needs of patients in line with their preferences and values. Patients are empowered to actively participate in their own care and clinical decision making. ${ }^{56}$

Patient-centred care has to be holistic, with multiple components being integrated in each patient-doctor encounter. ${ }^{7}$ At the core of patient-centred care is patient-centred communication (PCC). It needs to be cultural sensitive but meanwhile encourages shared decision making. Extensive studies have been conducted with a focus on improving communication between healthcare providers and their patients. ${ }^{8}$ Empirical evidence shows that effective communication is crucial to high quality care as measured by patient 
experience and patient care outcomes. ${ }^{9}$ Indeed, patientcentredness itself has become one of the indicators of quality care in the 21 st century. ${ }^{10}$ It represents a serious challenge to the traditional medical approach of paternalism. ${ }^{11}$ However, our understanding on the tendency of medical professionals towards patient-centredness is very limited. ${ }^{12}$

Arguably, PCC requires a harmonious doctor-patient relationship. Unfortunately, China is currently experiencing serious challenges in relation to the doctorpatient relationship. Medical disputes are frequently reported. There exists a crisis of distrust and mistrust between medical professionals and patients due to a wide range of reasons within and outside of the health sector. The disharmony between medical professionals and patients has been deemed a major obstacle of the health system reform. ${ }^{13}$ According to the 2017 'White Paper on Medical Workforce in China', only half of medical workers believed that their contributions were appreciated by the society. More than $65 \%$ experienced disputes with their patients and $62 \%$ were dissatisfied with their working environment. ${ }^{14} \mathrm{~A}$ lack of patient-centredness can fuel distrust and mistrust from the patients. Therefore, medical professionals can should play a vital role in building a harmonious doctor-patient relationship through patient-centred care. ${ }^{15}$ However, a perception of poor doctor-patient relationship may deter medical professionals from adopting a PCC approach in clinical practices. ${ }^{16}$

This study aimed to advance our understanding on the preference of medical professionals in China towards patient-centredness in clinical communication. The study adopted the Patient-Practitioner Orientation Scale (PPOS) to measure PCC. The PPOS was developed by Krupat et al, ${ }^{17}$ containing 18 items measuring two dimensions 'sharing' and 'caring.'. ${ }^{18}$ The caring dimension assesses the tendency of treating patients as a whole person, concerning their medical conditions and emotional and social needs. The sharing subscale assesses willingness of medical professionals to share information and decision-making power with their patients. ${ }^{19}$ It has been validated in a variety of study settings, including in the USA, Sri Lanka, Greece, Nepal, South Korea and Sierra Leone. ${ }^{79-23}$

Although PCC has started to gain momentum in China, there are only a few studies documenting the attitudes of medical professionals in China towards patientcentredness in clinical communication. Ting et al made the earliest known attempt to apply the PPOS to assess patient preference towards PCC in a hospital in the southwest of China. ${ }^{3}$ Since then, the Chinese-Revised PatientPractitioner Orientation Scale (CR-PPOS) has been validated in the medical professionals and the patients in Shanghai. ${ }^{24}$ However, there is paucity in the literature documenting the preference of medical professionals in other regions in China towards patient-centredness. Significant regional disparities in economic development exist in China, which has a profound impact on health resources and health services.
This study addressed the gap in the literature by conducting a cross-sectional study of the medical professionals in China's oldest industrial base - H City in Heilongjiang province using the CR-PPOS.

\section{MATERIALS AND METHODS}

\section{Study population and data collection}

A cross-sectional questionnaire survey of medical professionals was conducted in January and February 2018. Study participants were recruited through a stratified sampling strategy to ensure representativeness. Seven medical institutions in $\mathrm{H}$ City were selected first considering a balance of size and economic zones. Eligible medical professionals from the participating institutions were invited to participate in the survey. The eligibility criteria included: (1) full-time employees of registered medical doctors in various disciplines including anaesthetists and (2) working in clinical practice for at least 1 year. Those who were not registered medical doctors (such as nurses) and were absent on the day of data collection were excluded. The survey was voluntary and the respondents had to be able to complete the questionnaire independently without assistance. The survey was open to each hospital for 1 day or one and a half days.

The questionnaire was distributed in person to the study participants by 14 trained investigators. They explained the purpose and the study protocol in line with the informed consent letter to the participants in groups before distributing the questionnaire. They also provided instructions about how to fill in the questionnaire. Verbal informed consent was obtained from the participants prior to the commencement of the survey. Completion and return of the completed questionnaire was voluntary and anonymous. The respondents did not have to complete the questionnaire on the same day although most did so. In cases where the respondents wanted to participate but were unable to complete the questionnaire on the same day, another date was set up in negotiation with the respondents. Collection of the returned questionnaires started approximately $15 \mathrm{~min}$ after the questionnaire distribution. The investigators checked completeness of each returned questionnaire. Missing data, if found, were filled through a request with the original respondents.

In total, 650 questionnaires were distributed and 618 $(95.1 \%)$ valid questionnaires were obtained. The sample represented $10.9 \%$ of all registered medical professionals (nearly 5686 as of 2017) in H City.

\section{Patient and public involvement}

There was no patient and public involvement.

\section{Questionnaire design}

The original PPOS contains 18 items. The CR-PPOS reduced the number of items to 11 , which demonstrated better psychometric properties and high overall reliability and validity. ${ }^{24}$ In this study, we adopted the CR-PPOS with the consent from the authors of both PPOS and CR-PPOS. 
Each item was rated on a six-point Likert scale: $1=$ 'strongly disagree', 2='disagree', 3='somewhat disagree', 4='somewhat agree', $5=$ ' agree' and $6=$ 'strongly agree'.

The questionnaire also collected the sociodemographic characteristics (gender, age, marital status and educational attainment) and work experience (years of working, seniority and daily workload) of the respondents. In addition, we assessed the degree of satisfaction of the respondents with their income and their perceived relationship with patients. It is not uncommon in China for medical professionals to complain about their income, which can adversely affect their relationship with patients. ${ }^{14}$ Such a problem is particularly profound in the less developed regions of China.

\section{Statistical analysis}

Frequency distributions of respondents across different groups were described, which included gender (male or female), age ( $\leq 25,26 \sim 30,31 \sim 40$ and $>40$ years), marital status (unmarried, married, divorced and others), educational attainment (<bachelor, bachelor degree and postgraduate degree), years of working $(\leq 5,6 \sim 10$ and $>10)$, professional title (senior, sub-senior, intermediate, primary and no title), satisfaction with income (no or yes) and perceived harmonious doctor-patient relationship (no or yes).

The scores of the CR-PPOS items were aligned to the same direction before a summed score was calculated for the 'caring' and 'sharing' dimensions and the entire scale. They were described using mean values and SD. A higher score indicates a higher preference toward patientcentredness. The reliability of the CR-PPOS scale was assessed using Cronbach's $\alpha$ coefficient. A Cronbach's $\alpha$ of above 0.6 was deemed acceptable. Confirmatory factor analysis was performed to assess the construct validity of the CR-PPOS scale. Root mean square error of approximation (RMSEA <0.08), incremental fit index $(>0.90)$ and comparative fit index $(\mathrm{CFI}>0.90)$ were examined to assess fitness of the data into the model.

The 'sharing', 'caring' and total scores of the CR-PPOS were dichotomised using the median value $(15,21$ and 37 , respectively) as a cut-off point. A more patient-centred approach was assigned with a value of 1 , otherwise 0 . Multivariate logistic regression models were established to identify the sociodemographic (gender, age, marital status and educational attainment) and work experience (years of working, seniority, satisfaction with income, daily workload and perceived doctor-patient relationship) predictors of the preference towards patient-centredness. Adjusted OR and its 95\% CI for each tested predictor was presented.

The statistical analyses were performed using SPSS V.19.0 (IBM Corporation) and AMOS V.21.0.

\section{RESULTS}

\section{Sociodemographic characteristics of respondents}

About half respondents were female and in the age between 31 and 40 years. Over $76 \%$ of respondents were married at the time of the survey. Intermediate professional title was the most common title (38.6\%), followed by primary

\begin{tabular}{|c|c|c|}
\hline Characteristic & $\mathbf{N}$ & $\%$ \\
\hline \multicolumn{3}{|l|}{ Gender } \\
\hline Male & 311 & 50.3 \\
\hline Female & 307 & 49.7 \\
\hline \multicolumn{3}{|l|}{ Age (years) } \\
\hline$\leq 25$ & 30 & 4.9 \\
\hline $26 \sim 30$ & 136 & 22.0 \\
\hline $31 \sim 40$ & 323 & 52.3 \\
\hline$>40$ & 129 & 20.9 \\
\hline \multicolumn{3}{|l|}{ Marital status } \\
\hline Unmarried & 134 & 21.7 \\
\hline Married & 471 & 76.2 \\
\hline Divorced and others & 13 & 2.1 \\
\hline \multicolumn{3}{|l|}{ Years of working } \\
\hline$\leq 5$ & 243 & 39.5 \\
\hline $6 \sim 10$ & 165 & 26.8 \\
\hline$>10$ & 207 & 33.7 \\
\hline \multicolumn{3}{|l|}{ Professional title } \\
\hline Senior & 66 & 10.7 \\
\hline Subsenior & 104 & 16.9 \\
\hline Intermediate & 237 & 38.6 \\
\hline Primary & 168 & 27.4 \\
\hline No title & 39 & 6.4 \\
\hline \multicolumn{3}{|c|}{ Educational attainment } \\
\hline$<$ Bachelor & 4 & 0.6 \\
\hline Bachelor degree & 171 & 27.7 \\
\hline Postgraduate degree & 443 & 71.7 \\
\hline \multicolumn{3}{|c|}{ Satisfaction with income } \\
\hline No & 533 & 89.0 \\
\hline Yes & 66 & 11.0 \\
\hline \multicolumn{3}{|c|}{ Harmonious doctor-patient relationship } \\
\hline No & 553 & 89.6 \\
\hline Yes & 64 & 10.4 \\
\hline
\end{tabular}

title $(27.4 \%)$. The majority of respondents $(71.7 \%)$ had a postgraduate degree. Only a tenth of respondents were satisfied with their income and perceived a harmonious relationship with patients (table 1 ).

\section{Reliability and validity of the CR-PPOS scale}

The Cronbach's alpha coefficients of the CR-PPOS scale exceeded 0.7 , indicating good internal consistency (table 2).

The Bartlett's sphericity test yielded a value of 1457.716 $(\mathrm{df}=55, \mathrm{p}<0.001)$, and the Kaiser-Meyer-Olkin (KMO) index was 0.780 , indicating appropriateness for factor analyses. The confirmatory factor analysis showed a weak model fit: RMSEA $=0.100 ; \mathrm{CFI}=0.880 ; \mathrm{IFI}=0.882$. The results indicate a need for further revisions. 
Table 2 The internal consistency of the CR-PPOS

\section{Cronbach's $\alpha$}

\begin{tabular}{ll}
\hline Sharing subscale & 0.705 \\
Caring subscale & 0.739 \\
Total score & 0.720 \\
\hline
\end{tabular}

CR-PPOS, Chinese-Revised Patient-Practitioner Orientation Scale.

Item-to-component and item-to-total correlations

The Pearson correlation coefficients showed strong item-to-component correlations: $0.573-0.705$ for sharing $(\mathrm{p}<0.05)$ and $0.613-0.775$ for caring $(\mathrm{p}<0.05)$; and moderate item-to-total correlations: $0.372-0.613$ for sharing $(\mathrm{p}<0.05)$ and $0.495-0.617$ for caring $(\mathrm{p}<0.05)$. Both sharing and caring were highly correlated with the total CR-PPOS scores $(\mathrm{p}<0.001)$ despite a weak correlation between the sharing and caring scores $(0.2$, $\mathrm{p}<0.001$ ) (table 3).

\section{CR-PPOS scores}

The respondents had a mean sharing score of 15.26 $(\mathrm{SD}=4.21)$, compared with a mean caring score of 20.42 $(\mathrm{SD}=4.42)$. The total CR-PPOS score reached $35.62 \pm 6.64$. The highest item score was found in the question 'If doctors are truly good at diagnosis and treatment, the way they relate to patients is not that important' $(4.68 \pm 1.23)$. Whereas, the lowest score was found in the question 'Patients should rely on their doctors' knowledge and not try to find out their conditions on their own' $(2.08 \pm 0.94)$ (table 3).

Predictors of patient-centredness in clinical communications The multivariate logistic regression models showed that the respondents who had a postgraduate degree

Table 3 CR-PPOS item and scale scores and their correlations

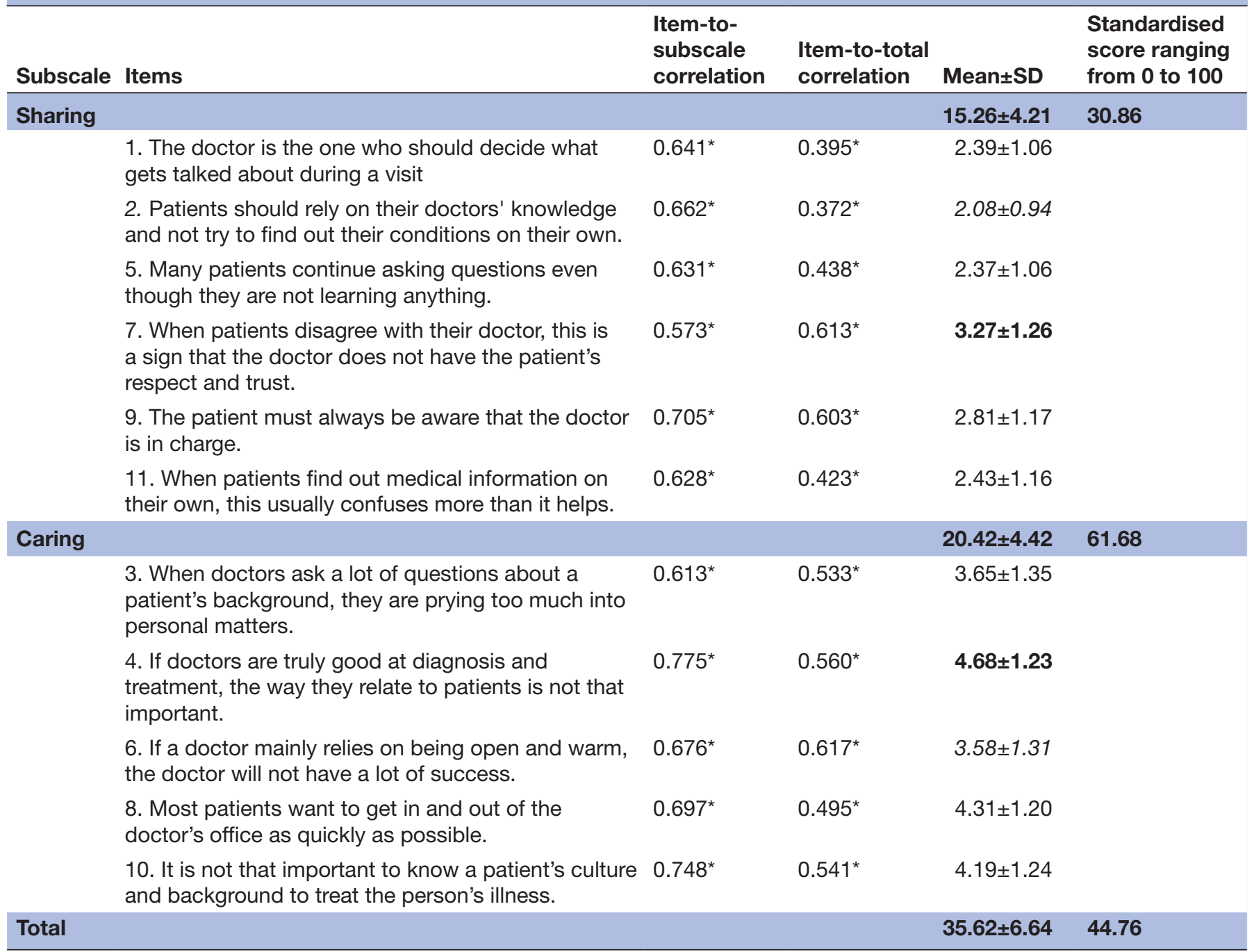

Notes: $\mathrm{p}<0.001$; score of 1 (strongly agree)=most clinician-centred; score of 6 (strongly disagree)=most patient-centred.

Bold values signifies the item has highest score.

Italic values signifies the item has lowest score.

*Spearman correlation coefficients.

CR-PPOS, Chinese-Revised Patient-Practitioner Orientation Scale. 
Table 4 Logistic regression analyses on factors associated with patient-centredness in clinical communications

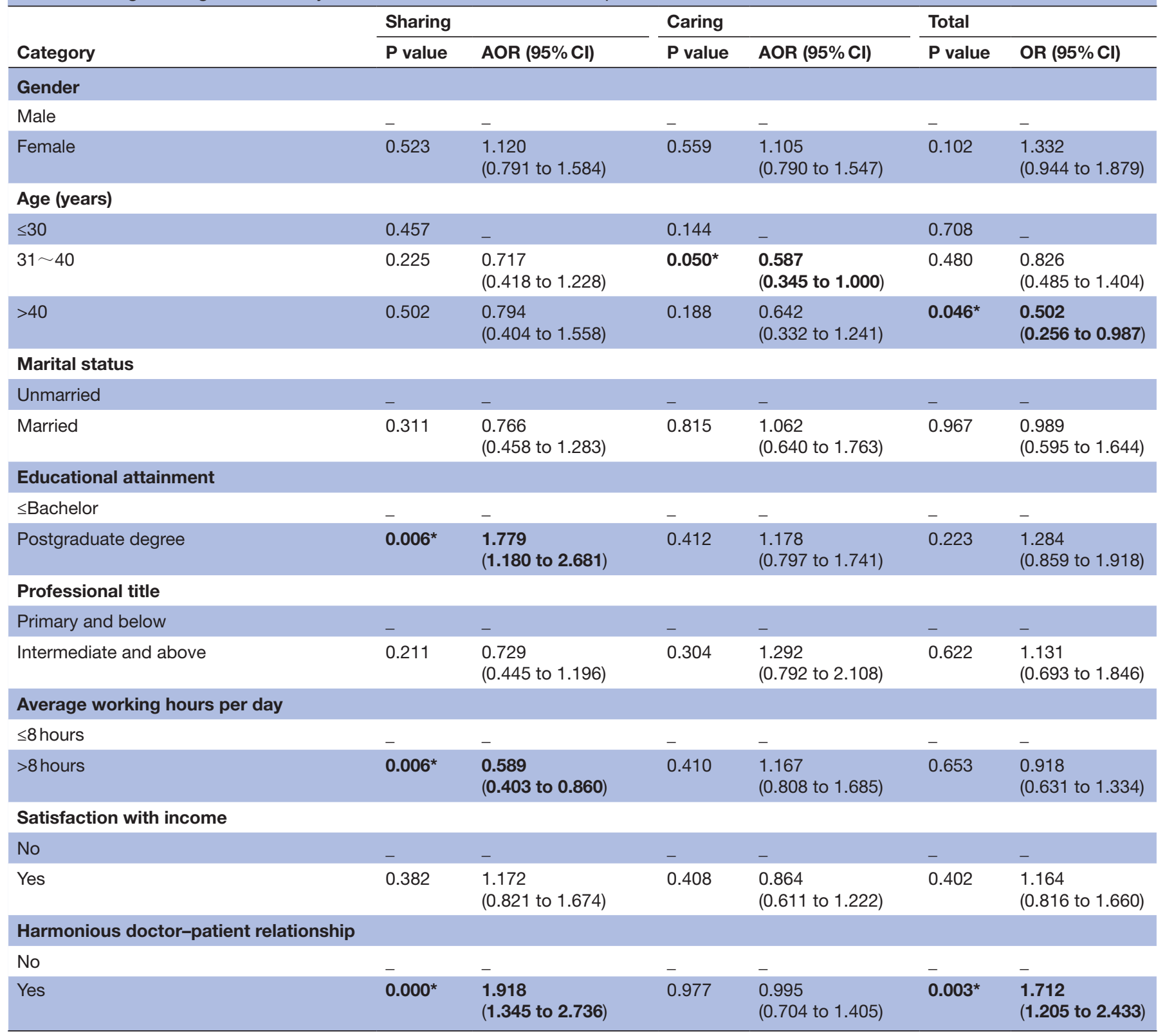

(Adjusted odds ratio $(\mathrm{AOR})=1.779,95 \% \mathrm{CI} 1.180$ to 2.681), worked less than 8 hours per day $(\mathrm{AOR}=0.589$, $95 \%$ CI 0.403 to 0.860 ) and perceived a harmonious doctor-patient relationship (AOR $=1.918$, 95\% CI 1.345 to 2.736 ) were more likely than others to agree with sharing information and decision power. The respondents aged between 31 and 40 years were marginally less likely to agree with caring centred around patients than their younger counterparts $(\mathrm{AOR}=0.587,95 \%$ CI 0.345 to 1.000$)$. In terms of the total scores, the respondents aged over 40 years were less likely to endorse patientcentredness $(\mathrm{AOR}=0.502,95 \% \mathrm{CI} 0.256$ to 0.987$)$ than their younger counterparts, but those who perceived a harmonious doctor-patient relationship were more likely to endorse patient-centredness $(\mathrm{AOR}=1.712$, $95 \%$ CI 1.205 to 2.433 ) (table 4 ).

\section{DISCUSSION}

Although the PPOS has been widely used in the international community and its Chinese version (CR-PPOS) has also been made available, ${ }^{719-23}$ only a few studies reported the results in China using the CR-PPOS. ${ }^{24}$ This study represents the first attempt of using the CR-PPOS to measure the attitudes of medical professionals toward patient-centredness in the northeast region of China. The CR-PPOS demonstrated good internal consistency.

Overall, the study participants reported an attitude not in favour of patient-centredness in clinical communication, with the standardised score below 50. The participants gave a relatively higher rating on caring (standardised score of 62) than on sharing (standardises score of 31). This pattern is consistent with the findings of most existing studies. However, there are two exceptions. 
The studies in Portugal and Australia revealed relatively higher scores in sharing compared with caring. ${ }^{25}{ }^{26}$ The underlying reasons are unknown. However, it is likely to be associated with the professional culture and local medical system environments. Further comparative studies are warranted.

In some studies, the PPOS scores were ranked and categorised into three groups using an average item score of 5 indicating a high preference, 4.57-4.59 indicating a medium preference and less than 4.57 indicating a low preference towards patient-centredness. ${ }^{18}$ Our study participants would be deemed to have extremely low preference towards patient-centredness using these criteria despite a slightly higher tendency towards caring for the needs of the whole person. Indeed, the mean item scores $(3.24 \pm 0.604)$ revealed in this study are lower than those found in the studies in Shanghai $(3.66 \pm 0.59),{ }^{24}$ the US Pilgrim Health Care (HPHC) $(4.26 \pm 0.75),{ }^{17}$ and Australia (4.46). ${ }^{25}$ The differences in the results may be partly explained by the differences in socioeconomic conditions and religious beliefs and cultural values. The attitudes of medical professionals may also change with the economic and health system development. ${ }^{27}$ The level of economic and health development in Shanghai has matched that of the developed countries. There exist great disparities between Shanghai and our study setting $\mathrm{H}$ City. The concept of patient-centred care in H City is still in its infant stage of development.

It is worth noting that the caring item 'If doctors are truly good at diagnosis and treatment, the way they relate to patients is not that important' attracted the highest score (4.68), indicating a relatively strong awareness of the study participants in regard to the need of skills beyond technical skills in caring for patients. There is consensus in medical professionals that patient care outcomes depend on shared goals and actions between patients and their care providers. ${ }^{26}$ This sentiment is support by the highest scored item in sharing 'When patients disagree with their doctor, this is a sign that the doctor does not have the patients' respect and trust'. It indicates that the study participants understood that patients might want to engage in clinical decision making in a respectful way. It is concerning, however, that the study participants showed low confidence in the ability of patients to meaningfully engage in clinical decision making. The sharing question 'Patients should rely on their doctors' knowledge and not try to find out their conditions on their own' (2.08) and the caring question 'If a doctor mainly relies on being open and warm, the doctor will not have a lot of success' (3.58) attracted the lowest scores, respectively, suggesting that the study participants put very high values on their technical inputs in clinical communication. These results are generally consistent with the findings of other studies. $^{126}$

Both sociodemographic characteristics and working environmental factors are associated with the attitudes of medical professionals towards patient-centredness in clinical communication. We found in this study that higher workloads are associated with a lower preference towards patient-centredness. Previous studies revealed that high workloads of health workers have become a serious concern in China, which can lead to burnout. ${ }^{28}$ Burnout in turn can result in low job satisfaction, high incidence of medical errors, worsened relationship with patients ${ }^{27} 29$ and even avoidance of direct contacts with patients. ${ }^{30}$ It is hard to imagine how a medical doctor experiencing burnout can dedicate time and efforts to share information and power and address the concerns and choices of their patients. ${ }^{27}$

An interesting finding of this study is that a perceived harmonious relationship with patients is positively associated with the preference towards patient-centredness in clinical communication, especially in regard to sharing information and decision-making power. A plausible explanation is that those who perceive a harmonious doctor-patient relationship may place high trust in their patients and are less likely to be hesitated to share information and power with their patients. The growing medical disputes reported in China may become a serious barrier for promoting patient-centredness in clinical communication. ${ }^{3}$ Medical professionals desire a process of communication built on mutual respect and mutual understanding.

Education can also play a role in promoting patientcentredness. Our study found that the study participants with a postgraduate qualification were more likely to prefer sharing information and power with patients. The medical educational curricula may have contributed to the results. ${ }^{31}$ There has been a lack of emphasis on the communication components in vocational training curricula for medical practitioners. Researchers have called for strengthening the educational role of medical practitioners for their patients. ${ }^{32}$ It appeared that the medical training curricula in China may have started to adapt to the changing trend. ${ }^{31}$ The younger medical professionals in this study were found to have a relatively higher preference towards patient-centredness in clinical communication.

\section{Strengths of this study}

This is the first study of its kind to report the attitudes of medical professionals in the northeast of China towards patient-centred care. Low levels of preference towards patient-centredness in clinical communication were found. Findings of this study have significant implications on the management of medical practice under the specific context of China. The sample size of this study was large, which enabled us to identify the sociodemographic and work experience predictors of the attitudes towards patient-centredness.

\section{Limitations and suggestions for future research}

The study adopted a cross-sectional design. No causal relationships can be assumed. It is also important to note the short survey period. The attitudes of medical professionals may change over time. In addition, the participants 
in this study were sampled from seven medical institutions in $\mathrm{H}$ City, which limits the external validity of the study and generalisability of the findings. Further studies are needed in a more representative large sample, which can include a comparative study across different regions and settings. It is also important to understand the view of patients on this matter. A longitudinal study is also desired to determine changes in the attitudes of medical professionals over time.

\section{CONCLUSIONS}

Overall, the survey revealed a low preference of medical professionals in the northeast of China towards patientcentredness in clinical communication. A relatively higher preference towards caring was found in comparison with sharing. Younger age, higher education, lower working loads and a perception of harmonious doctorpatient relationship are significant predictors of more favourable attitudes towards patient-centredness in clinical communication.

Improving medical education and working environments may be plausible strategies for promoting patientcentredness. However, the intense patient-provider relationship in China presents a serious challenge. It is equally important to empower patients and enhance their endorsement of partnership building with medical professionals. This should include the use of mass media. ${ }^{29}$

Training is important for improving the communication skills of medical professionals. However, training alone is not enough. The society as a whole and the entire healthcare system need to embrace the value and significance of patient-centred care.

\author{
Author affiliations \\ ${ }^{1}$ Department of Social Medicine,School of Health Management, Harbin Medical \\ University, Harbin, Heilongjiang, China \\ ${ }^{2}$ Department of Humanity and Social Sciences, Harbin Medical University, Daqing, \\ Heilongjiang, China \\ ${ }^{3}$ Academic Affair Office, Dean's Office of Clinical Medical College, Anhui Medical \\ University, Hefei, Anhui, China \\ ${ }^{4}$ Office of discipline supervision \& investigation, Chengyang People's Hospital, \\ Qingdao, Shandong, China \\ ${ }^{5}$ Department of Public Health,School of Psychology and Public Health, La Trobe \\ University, Melbourne, Victoria, Australia \\ ${ }^{6}$ College of International Education, Qiqihaer Medical University, Qiqihaer, \\ Heilongjiang, China
}

\section{Twitter Wei Liu@15764504915@163.com}

Acknowledgements We sincerely thank Dr. Edward Krupat from Harvard Medical School for generously sharing information and giving valuable advice regarding the PPOS. We are also grateful to Jie Wang and Fan Wang from Fudan University for developing the CR-PPOS. We would like to thank all of the study participants and participating institutions for their involvement and support.

Contributors WS and MJ contributed equally as the first author to this article. $\mathrm{LL}$ and QW designed the study and collected the data , and LL responsible for the overall content as the guarantor. $\mathrm{YC}, \mathrm{YH}$ and $\mathrm{XZ}$ provided statistical expertise. CL critically revised the manuscript. WL and ST analysed the data. YX and JZ performed questionnaire translation and literature review. QZ provided administrative support. WX, HS, YL and LS made critical revisions to the paper for important scientific content and reviewed various drafts as well as the final manuscript. All authors read and approved the final manuscript.
Funding This work was supported by the National Natural Science Foundation of China (Grant Number: 71673073, 71974049), Heilongjiang Postdoctoral Scientific Research Development Fund (LBH-Q18071), Think Tank of Public Health Security and Health Reform of Heilongjiang Province, special project supported by China Postdoctoral Foundation (2016T90318)

Disclaimer The funders had no role in study design, data collection and analysis, decision to publish, or preparation of the manuscript

Competing interests None declared.

Patient and public involvement Patients and/or the public were not involved in the design, or conduct, or reporting, or dissemination plans of this research.

Patient consent for publication Not applicable.

Ethics approval Ethical approval to conduct this study was granted by the research ethics committee of Harbin Medical University and informed consent to participate was obtained from each hospital and healthcare workers involved in the investigation. All respondents who gave their informed consent completed the questionnaire. Participants gave informed consent to participate in the study before taking part.

Provenance and peer review Not commissioned; externally peer reviewed.

Data availability statement Data are available on reasonable request. Data are available on reasonable request; additional data from this study could be accessed by contacting the corresponding author LL via Ilbhit@163.com.

Open access This is an open access article distributed in accordance with the Creative Commons Attribution Non Commercial (CC BY-NC 4.0) license, which permits others to distribute, remix, adapt, build upon this work non-commercially, and license their derivative works on different terms, provided the original work is properly cited, appropriate credit is given, any changes made indicated, and the use is non-commercial. See: http://creativecommons.org/licenses/by-nc/4.0/.

\section{ORCID iDs}

Weijian Song http://orcid.org/0000-0001-8487-5848

Chaojie Liu http://orcid.org/0000-0003-0877-0424

Mingli Jiao http://orcid.org/0000-0001-7405-5571

Libo Liang http://orcid.org/0000-0002-4444-9497

Qunhong Wu http://orcid.org/0000-0002-2873-5266

\section{REFERENCES}

1 Manchaiah V, Gomersall PA, Tomé D, et al. Audiologists' preferences for patient-centredness: a cross-sectional questionnaire study of cross-cultural differences and similarities among professionals in Portugal, India and Iran. BMJ Open 2014;4:e5915.

2 Chan $\mathrm{CMH}$, Wan Ahmad WA, Yusof MM, et al. Patient-Centredness, job satisfaction and psychological distress: a brief survey comparing oncology nurses and doctors. Asian Pac J Cancer Prev 2015;16:6895-8.

3 Ting $X$, Yong B, Yin L, et al. Patient perception and the barriers to practicing patient-centered communication: a survey and in-depth interview of Chinese patients and physicians. Patient Educ Couns 2016;99:364-9.

4 Ribeiro MMF, Krupat E, Amaral CFS. Brazilian medical students' attitudes towards patient-centered care. Med Teach 2007;29:e204-8.

5 Castro EM, Van Regenmortel T, Vanhaecht K, et al. Patient empowerment, patient participation and patient-centeredness in hospital care: a concept analysis based on a literature review. Patient Educ Couns 2016;99:1923-39.

6 Health I OMU, Delivery C. Envisioning the National Health Care Quality Report[M. Washington (DC: National Academies Press (US), 2001.

7 Lau SR, Christensen ST, Andreasen JT. Patients' preferences for patient-centered communication: a survey from an outpatient department in rural Sierra Leone. Patient Educ Couns 2013;93:312-8.

8 Cegala DJ. Patient communication skills training: a review with implications for cancer patients. Patient Educ Couns 2003;50:91-4.

9 Charlton CR, Dearing KS, Berry JA, et al. Nurse practitioners' communication styles and their impact on patient outcomes: an integrated literature review. J Am Acad Nurse Pract 2008;20:382-8.

10 America I OMU. Crossing the Quality Chasm: A New Health System for the 21st Century[M]. Washington (DC): National Academies Press (US), 2001.

11 Taylor K, Paternalism TK. Paternalism, participation and partnership - the evolution of patient centeredness in the consultation. Patient Educ Couns 2009;74:150-5. 
12 Haidet P. Patient-centredness and its challenge of prevailing professional norms. Med Educ 2010;44:643-4.

13 Yi Y, Yanhua H, Libo L. Analysis of medical staff perspective factors influencing a harmonious doctor-patient relationship: Based on 27 public hospitals of Heilongjiang province[J]. Chinese Journal of Health Policy 2016;9:15-19.

14 . Available: http://www.199it.com/archives/673838.html

15 Jianhua Z, Wenjie T, Min T. Influencial Factors Analysis and Policy Selection of Physician-Patient Relationship in View of Hospital and Medical Staff[J]. Chinese Medical Ethics 2011;24:123-5.

16 Roter $\mathrm{D}$. The enduring and evolving nature of the patient-physician relationship. Patient Educ Couns 2000;39:5-15.

17 Krupat E, Rosenkranz SL, Yeager CM, et al. The practice orientations of physicians and patients: the effect of doctor-patient congruence on satisfaction. Patient Educ Couns 2000;39:49-59.

18 Krupat E, Hiam CM, Fleming MZ, et al. Patient-centeredness and its correlates among first year medical students. Int J Psychiatry Med 1999;29:347-56.

19 Mudiyanse RM, Pallegama RW, Jayalath T, et al. Translation and validation of patient-practitioner orientation scale in Sri Lanka. Educ Health 2015;28:35-40.

20 Shaw WS, Woiszwillo MJ, Krupat E. Further validation of the PatientPractitioner orientation scale (PPOs) from recorded visits for back pain. Patient Educ Couns 2012;89:288-91.

21 Tsimtsiou Z, Kirana P-S, Hatzichristou D. Determinants of patients' attitudes toward patient-centered care: a cross-sectional study in Greece. Patient Educ Couns 2014;97:391-5.

22 Moore M. What does patient-centred communication mean in Nepal? Med Educ 2008;42:18-26.

$23 \mathrm{Kim} \mathrm{M}-J$. [Differences in attitude toward patient-centeredness in patients and physicians]. Korean J Med Educ 2013;25:149-56.
24 Wang J, Zou R, Fu H, et al. Measuring the preference towards patient-centred communication with the Chinese-revised PatientPractitioner orientation scale: a cross-sectional study among physicians and patients in clinical settings in Shanghai, China. BMJ Open 2017;7:e16902

25 Laplante-Lévesque A, Hickson L, Grenness C. An Australian survey of audiologists' preferences for patient-centredness. Int J Audiol 2014;53 Suppl 1:S76-82.

26 Manchaiah V, Dockens AL, Bellon-Harn M, et al. Noncongruence between Audiologist and patient preferences for PatientCenteredness. J Am Acad Audiol 2017;28:636-43.

27 Ahmad W, Ashraf $\mathrm{H}$, Talat A, et al. Association of burnout with doctor-patient relationship and common stressors among postgraduate trainees and house officers in Lahore-a cross-sectional study. PeerJ 2018;6:e5519.

28 Lo D, Wu F, Chan M, et al. A systematic review of burnout among doctors in China: a cultural perspective. Asia Pac Fam Med 2018;17:3.

29 Akkafi M, Sajadi HS, Sajadi ZS, et al. Attitudes toward patientcentered care in the mental care services in Isfahan, Iran. Community Ment Health J 2019;55:548-52.

30 Wen J, Cheng Y, Hu X, et al. Workload, burnout, and medical mistakes among physicians in China: a cross-sectional study. Biosci Trends 2016;10:27-33

31 Hurley EA, Doumbia S, Kennedy CE, et al. Patient-Centred attitudes among medical students in Mali, West Africa: a cross-sectional study. BMJ Open 2018;8:e19224.

32 Hung L-M, Rane S, Tsai J, et al. Advancing primary care to promote equitable health: implications for China. Int J Equity Health 2012;11:2. 